\title{
OS NOVOS SENTIDOS PROMOVIDOS PELO LIVRO DIGITAL: proposta de análise como insumo para estratégias de design
}

\author{
NEW DIRECTIONS PROMOTED BY DIGITAL BOOK: \\ proposed analysis as input to design strategies \\ SCHERDIEN, Ingrid; Mestre. \\ Universidade do Vale do Rio dos Sinos - UNISINOS \\ ingridesigner@gmail.com \\ BENTZ, IONE M. G.; Doutora. \\ Universidade do Vale do Rio dos Sinos - UNISINOS \\ ioneb@unisinos.br
}

\begin{abstract}
Resumo: Considerando que as possibilidades que o meio eletrônico gera para a leitura digital podem estimular as editoras e autores a pensarem em novas formas de interação, até então impensáveis nas publicações impressas, este artigo tem como principal intenção discutir o livro digital no âmbito do design e dos processos midiáticos, abordando a reconfiguração das práticas de leitura e os novos sentidos promovidos pela digitalidade, na conjuntura do suporte eletrônico, do texto, das imagens e das interações. Os novos significados da leitura são exemplificados através da análise imanente do livro digital Little Red Riding Hood, desenvolvido pela empresa de aplicativos Bean Bag Kids. Essa análise pode servir como insumo para estratégias de design em novos projetos de sistemas produtoserviço para o livro digital.
\end{abstract}

Palavras-chave: livro digital, práticas de leitura, efeitos de sentido.

Abstract: Considering the possibility that the electronic means for generating digital reading can stimulate publishers and authors to think in new ways of interaction, hitherto unthinkable in print publications, this article has the intention to discuss the digital book within the design and media processes, addressing reconfiguration of reading practices and new directions promoted by digitality, at the juncture of the electronic media, text, graphics, and interactions. The news meanings are exemplified through the immanent analysis of the digital book called Little Red Riding Hood, developed by the company of applications Bean Bag Kids. This analysis can serve as input for design strategies in projects of Product Service Systems for the digital book.

Keywords: digital book, reading practices, sense effects. 


\section{INTRODUÇÃO}

Este artigo é resultado de questionamentos de pesquisa situados no âmbito dos processos midiáticos e da leitura digital. Leitura esta que intenciona a geração de novos sentidos e novas experiências que possibilitam a reconfiguração das práticas já assimiladas pelos leitores das mídias impressas. Este texto pretende somar-se às discussões sobre o livro digital, propondo uma abordagem que responda, ou pelo menos que dê indicativos, se a leitura digital promove ou não novos significados para os conteúdos contidos no novo meio tecnológico.

O estudo intenciona a discussão sobre o suporte e suas possibilidades geradas pela tecnologia de hardware e software, sobre as práticas já formatadas dos leitores e suas expectativas e sobre os efeitos de sentido gerados pela leitura digital, que podem determinar quais estratégias de design devem ser utilizadas na criação de sistemas produto-serviço para o mercado do livro digital. Ou seja, um conjunto de produtos, serviços e comunicação totalmente integrados.

Para tornar essas reflexões mais palpáveis, apresenta-se uma análise imanente, com base em determinado livro digital - um aplicativo contendo a história infantil Chapeuzinho Vermelho - Little Red Riding Hood, desenvolvido pela empresa de aplicativos Bean Bag Kids.

\section{O LIVRO DIGITAL NO CAMPO DA MÍDIA E DO DESIGN}

O livro, como um produto do campo da produção cultural e da mídia clássica, já passou por inúmeras transformações técnicas, morfológicas e simbólicas, conforme Labarre (1981). O autor afirma que, durante toda a história, o homem presenciou várias formas de materialização e utilização do livro. A mudança do formato volumen, que se apresentava sob a forma de um rolo, para o formato codex, com páginas sequenciais, pode ser considerada como uma mudança radical na história do livro, pois o atingiu em sua forma. As mudanças simbólicas promovidas pela cultura e pela sociedade também se fizeram presentes, desde a leitura em voz alta e em grupo com os rolos do volumen, até a leitura silenciosa e contemplativa do codex. Hoje, se estabelece outro momento de mudanças, no qual a digitalidade passa a ser o transformador das práticas culturais de leitura da sociedade. Segundo Furtado (2002), as transformações tecnológicas e sociais indicam uma mudança única em relação a todas as mudanças que ocorreram no livro do passado, demonstrando um real novo momento das publicações.

Considera-se o livro digital, também chamado de livro eletrônico ou e-book (electronic book), como o arquivo digital do conteúdo de um livro, podendo ter ou não uma versão impressa correspondente. Atualmente, encontram-se livros digitais em diversos formatos, principalmente em PDF, ePub e aplicativos que podem ser executados em computadores, e-readers dedicados, tablets, smartphones, videogames e outros dispositivos eletrônicos. O livro digital ainda encontra-se em uma fase de adaptação das suas formas de produção e distribuição de conteúdo.

Imagina-se que possa haver diferenças de sentido nas histórias em diferentes mídias. Esses processos de significação são importantes para a formação e consolidação do campo midiático, defendido por Rodrigues, A. (1999) como autônomo e capaz de pautar a sociedade. Para o autor, o ritmo da vida cotidiana é marcado pela dependência de dispositivos midiáticos que proporcionam uma nova percepção de mundo. Esses dispositivos se autonomizam em um campo próprio dotado de 
legitimidade para superintender à experiência de mediação, que faz emergir, nas fronteiras dos campos sociais instituídos, novas questões de natureza científica, política, econômica, religiosa e médica. Os assuntos discutidos nos livros, sejam eles baseados em fatos reais ou puramente ficção, contemplam as questões problematizadas na sociedade. Nesse mesmo contexto surge o livro digital, um novo produto cultural do campo da mídia e do design, gerando questionamentos sobre o que pode transformar na sociedade.

Mas essa transformação não se dará somente pela navegação em diferentes dispositivos midiáticos ou ainda por milhares de livros dentro do suporte eletrônico. A revolução realmente impactante diz respeito principalmente ao modo como as novas gerações consomem e compartilham o conteúdo e como geram os novos sentidos na leitura. Com a troca do suporte impresso para múltiplos suportes digitais, têm-se a possibilidade de promover fluxos de leitura contrários à linearidade e ainda o acréscimo de interatividade por meio de animações, vídeos e sons. Mas enquanto essa nova mídia digital processa a história contida no livro, não se sabe ao certo o que aconteceu com a história. Será que ela permanece a mesma, embora tenha quebras no fluxo linear e outros atrativos interativos? Será que os sentidos gerados são os mesmos das práticas de leitura de materiais impressos?

As práticas de leitura já configuradas representam o habitus dos leitores. Habitus, segundo Bourdieu (1998), é um conhecimento adquirido e também um haver. É adquirido pelas experiências vividas. Como afirma Farbiarz e Farbiarz (2010), a humanidade acumulou experiências, transformadas em repertório cultural, que foram sendo transferidas e adaptadas de uma geração à outra. Segundo Rodrigues, A. (1999), na origem da experiência, encontra-se o sistema de expectativas, que se constitui como um sistema simbólico que regula a vida do indivíduo de acordo com aquilo que ele foi habituado a esperar do comportamento dos outros, dos objetos ou da natureza. No caso do livro impresso, cada indivíduo, desde que aprendeu a ler, entendeu que o que se espera de um livro é que o texto contido nas páginas tenha uma sequência que facilite o entendimento, com início, meio e fim. O formato retangular, o suporte de papel e as páginas virando no sentido horizontal, também são características que se esperam no livro impresso. Esse habitus do leitor tradicional pode impedi-lo ou estimulá-lo a ferir seus padrões e produzir novas experiências e sentidos com o livro digital. No caso da história do personagem Chapeuzinho Vermelho, por exemplo, já lida e conhecida pela maioria das pessoas: quais informações vêm do habitus e o que o suporte e o software podem dizer de diferente no livro digital?

\section{SUPORTE ELETRÔNICO E CONTEÚDO, MEIO E MENSAGEM}

O avanço tecnológico proporciona a cada dia a criação de novos dispositivos eletrônicos que são desejados e consumidos pela maioria dos indivíduos. Passando de objetos de desejo para itens de necessidade, esses artefatos passam a fazer parte essencial do dia a dia da sociedade contemporânea.

McLuhan (2007) considera os meios como extensões dos sentidos humanos, aos quais os indivíduos se tornam dependentes dado o desenvolvimento tecnológico. Nessa abordagem, o homem prolonga-se para fora de si mesmo, em um modelo vivo do próprio sistema nervoso central. Rodrigues, A. (1999) também interpreta os dispositivos midiáticos como extensões artificiais dos órgãos dos sentidos, que colocam o mundo à disposição do indivíduo. As interpretações desses autores tornam- 
se cada vez menos metafóricas quando se analisa os produtos tecnológicos recentes. Vide as telas touchscreen de computadores, tablets, celulares e outros produtos, nos quais a sensibilidade com o toque humano é bastante precisa, eliminando a intercessão por outros objetos: não é mais necessário nem uma caneta magnética, tampouco botões, a tela artificial e os dedos humanos executam todas as funções como se fossem extensões reais um do outro.

Considerando a influência dos dispositivos eletrônicos na sociedade, ao abordar-se a temática do livro digital, certamente não se pode deixar de lado a importância do suporte como meio tecnológico. Para McLuhan (2007), considerando que é o meio que rege a forma e a dimensão dos atos e associações humanas, é reducionismo ter os meios apenas como caminhos que transportam os conteúdos. 0 próprio meio é uma mensagem e o conteúdo de um meio é sempre outro meio. 0 conteúdo também é um meio de divulgação e compartilhamento dos pensamentos do autor e dos leitores. As possibilidades que o meio eletrônico gera para a leitura digital podem estimular as editoras e autores a pensarem em novas formas de interação, até então impensáveis nas publicações impressas.

Os suportes eletrônicos proporcionaram ao livro novas possibilidades de leitura e diversos recursos multimídia e interativos, os quais o leitor dá início, ultrapassando os limites do texto escrito. Esse conjunto de recursos associado ao hipertexto constitui-se da hipermídia. Para Santaella (2007), com a linguagem da hipermídia, no livro digital a leitura pode ocorrer por caminhos distintos, em vez de um fluxo linear de texto, como é próprio da linguagem verbal impressa. Através dos hiperlinks, o leitor se desloca de um ponto ao outro do conteúdo, inclusive explorando informações externas ao livro.

Esse tipo de leitura hipermidiática remete à interpretação de Flusser (2007) e seu entendimento particular sobre o pensamento e a leitura em linhas e o pensamento e a leitura em superfícies. Para esse autor, a diferença entre ler linhas escritas de um livro, por exemplo, e ler uma pintura, ou seja, uma superfície, tem a ver com o fato de que no livro impresso, para se captar a mensagem, precisa-se seguir o texto, enquanto na pintura, pode-se aprender a mensagem e depois tentar decompôla. Na leitura de um livro impresso, faz-se basicamente a leitura em linha: lê-se o texto da esquerda para direita, de cima para baixo, de uma página para outra. Em um livro digital mimetizado também encontramos basicamente o mesmo processo. $O$ que se propõe a discutir é interpretar as considerações de Flusser (2007) e entender o livro digital hipermidiático como uma leitura em superfície, ao possibilitar o controle e a manipulação do leitor sobre a sequência do conteúdo textual e imagético. Atuar sobre o conteúdo, buscar compreender a mensagem rapidamente como um todo, decompôla em pequenas partes, ou ainda ler de modo integral, são escolhas do leitor.

Assim, se a transformação do meio é tão intensa, capaz de modificar a formatação do produto livro e seus usos, acredita-se que ler em múltiplos e diferentes suportes pode modificar as práticas e sentidos da leitura. Seguindo o entendimento de uma linha de análise que privilegia uma visão na qual a leitura é uma prática criadora e polissêmica, para Chartier (1996) os atos de leitura dão ao texto significações plurais e móveis, e as maneiras de ler sofrem influência do modo como o texto é apresentado materialmente. Para o autor, não existe nenhum texto fora de seu suporte, nem compreensão do texto que não dependa das formas através das quais ele chega ao leitor. Para Farbiarz e Farbiarz (2010), o conteúdo pode ser apresentado de diferentes 
formas e as formas diferenciadas que os livros assumem modificam o significado dado pelo leitor.

Nesse contexto, parte-se então para a análise imanente do aplicativo Little Red Riding Hood, desenvolvido pela empresa de aplicativos Bean Bag Kids. Com essa análise, torna-se mais palpável o conceito do livro digital e os significados que ele gera, além de trazer de modo mais presente a questão do design, prático e estratégico, nos livros digitais.

\section{A PRODUÇÃO DE NOVOS SENTIDOS NO LIVRO DIGITAL: ANÁLISE DO APLICATIVO}

Pesquisando diversos autores, Farbiarz e Farbiarz (2010) chegaram à conclusão de que as variáveis na produção de sentidos da leitura contemplam o momento da leitura, o contexto sócio histórico-cultural e o repertório do leitor, integrando o discurso e o suporte. Conforme Goulemot (1996), no momento da leitura se inclui, além da relação do corpo do leitor para com o objeto livro, também o seu entorno, o lugar onde está e até mesmo seu estado de ânimo. O contexto sócio histórico-cultural influencia o repertório, composto por conhecimentos e ideias que antecedem o momento da leitura.

Sendo assim, a análise do aplicativo do livro digital em questão, além de compreender como influência o meio tecnológico - no caso da análise deste artigo, o iPhone -, compreende também as autoras do artigo não só como analistas, mas como macro leitoras, que carregam conceitos formados pelos seus contextos culturais. Não haveria como ser diferente, pois se considera que o pesquisador não é neutro. Mas as interpretações aqui descritas podem ser posteriormente submetidas a um corpo de juízes que tem a capacidade de acrescentar e de corrigir determinados pontos, validando assim, as considerações feitas.

Talvez haja a possibilidade de questionar a interpretação de um macro leitor adulto que já conhece a história, sendo que o livro é destinado também ao público infantil. Uma criança que ler o livro pela primeira vez, certamente terá a primeira construção de seu entendimento e interpretação, sem ter parâmetros de comparação. Porém, o que se pretende com essa análise é descobrir quais os novos sentidos que o livro digital é capaz de promover, considerando que a geração desses sentidos pode não ter sido proposital por parte da editora ou desenvolvedora do aplicativo. Por outro lado, pretende-se entender que sentidos são esses, de modo a compreender que tipos de decisões estratégicas projetuais podem ser tomadas para o desenvolvimento de sistemas produto-serviço para o design de novos livros digitais.

Jensen (1997) contribui bastante para essa análise considerando a semiótica, que analisa os fenômenos culturais como sistemas de significação. A análise semiótica faz com que se tenha mais atenção ao papel mediador dos signos para a construção da realidade social. Considerando o livro digital, pretende-se verificar quais significados mediam a ação do interpretante, ou seja, do leitor, e a estrutura, que é o objeto livro digital. O que se pretende é realizar uma análise imanente e ler, não somente o texto, mas o design, a interface e os significados do aplicativo, analisando cada parte e assim compreendendo o todo.

Em relação ao design, na visão de Frascara (2004) os objetos visuais carregam mensagens específicas que se constituem pela orientação do designer, que atua na construção e na comunicação de significados. Para Flusser (2007), também o design atribui significados aos objetos e informações, mediando a comunicação. Dimensão 
comunicacional esta que, para Jensen (1997) precisa circular, fazendo com que significar e transitar sejam praticamente uma implicação social.

Para melhor compreender as análises é importante contextualizar a história contida no livro digital analisado. Esta se trata do conto da Chapeuzinho Vermelho, que de acordo com o senso comum possui muitas versões, algumas mais assustadoras, com finais não tão felizes, como a própria versão original do francês Charles Perrault, publicada em 1697, na qual tanto a vovozinha quanto a menina morrem. Mas há outras versões mais amenas, como a dos irmãos Grimm, de 1812, na qual a menina e a vovozinha são salvas pelo lenhador. Esta última visa ensinar conceitos para as crianças, como não falar com estranhos ou desobedecer aos pais. Há mudanças também quanto ao que a menina levaria na cesta para sua vovozinha, se doces, pão e leite ou bolo e vinho. A versão mais comumente conhecida apresenta a menina Chapeuzinho Vermelho como uma garota gentil que usava uma capa vermelha. A pedido de sua mãe, ela leva uma cesta para sua avó, mas no caminho encontra um lobo que a convence a desviar-se do trajeto para colher flores. Enquanto isso, o lobo vai até a casa da vovozinha e a come, vestindo suas roupas e passando-se por ela. Quando a menina chega, estranha sua vovozinha e faz as clássicas exclamações: "Que orelhas grandes você tem! Que olhos grandes você tem! Que boca grande você tem!" Ao que o lobo afirma que é para comer melhor a Chapeuzinho Vermelho e a devora, como havia feito com sua avó. Mas um lenhador que passava por perto percebe os acontecimentos, abre a barriga do lobo, salva as duas e coloca pedras no lugar, matando o lobo.

$\mathrm{O}$ aplicativo de livro digital para tablet e smartphone analisado neste artigo conta a história da Chapeuzinho Vermelho de um modo peculiar. A história é praticamente a mesma, com exceção de que não é mencionado o fato do lobo engolir a vovozinha, apenas referencia-se que ela foi atacada por ele. Também a Chapeuzinho Vermelho não é engolida, apenas perseguida. Dessa forma, o lenhador captura o lobo, mas não há nenhuma menção quanto a cortar sua barriga ou matá-lo. Com isso, vê-se que há a intenção de deixar a história ainda mais amena, isto porque seriam as próprias crianças os fantoches Bean Kids - que reproduziriam o conto, objetivando uma leveza em conformidade com os aspectos gráficos do visual ilustrado do aplicativo.

A empresa desenvolvedora, que assume o papel de editora do e-book, se intitula como Bean Bag Kids, que remete aos pufes e bonecos de pelúcia preenchidos com micro bolinhas em espuma, isopor ou PVC, maleáveis como sacos de feijões. As crianças do saco de feijões, como a própria empresa denomina, são um grupo de amigos bonitos e fofinhos que gosta de brincar vestindo fantasias e encenando histórias virtuais (Figura 1). Desse modo, cada ator mirim virtual adota um personagem e em conjunto apresentam uma narrativa. Em 2011, o primeiro aplicativo, Little Red Riding Hood, foi lançado gratuitamente para download na Apple Store. Em 2012, Pinocchio, com o custo de 2,99 dólares.

Figura 1 - Bean Kids: personagens do aplicativo.

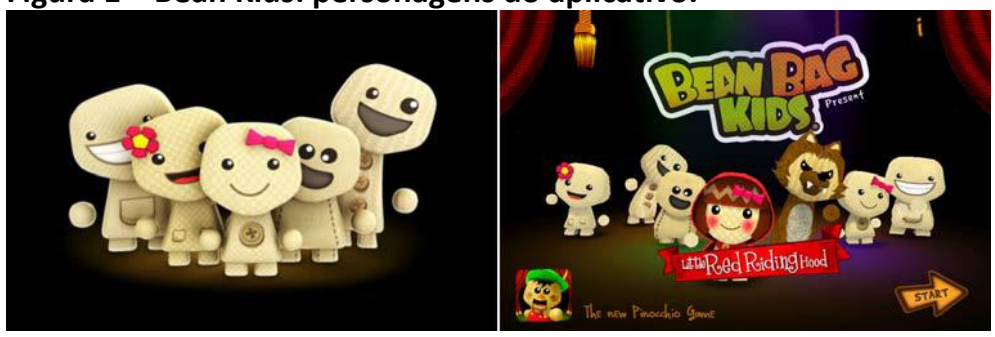

Fonte: BEAN BAG KIDS (2011). 
Por propor novos personagens e uma narrativa diferenciada, pode-se considerar a empresa como autora, além de editora. Isso representa uma nova manifestação no campo midiático com a transferência do domínio e do poder simbólico de algumas editoras para empresas independentes, que procuram alcançar com mais agilidade e eficiência os desejos dos leitores na era da digitalidade. Em relação ao aplicativo propriamente dito, utiliza muitos dos recursos que o meio tecnológico possibilita, como áudio (narrativa, ruídos e canções) e animações em 3D, e se propõe a ser bastante interativo. No decorrer das telas é possível tocar nos personagens e interagir com eles, como por exemplo, fazer a Chapeuzinho Vermelho abanar e cheirar as flores, o lobo mau correr de uma árvore para outra, roncar e grunhir, a mãe da Chapeuzinho Vermelho sorrir, o lenhador balançar seu machado, a vovó bater palmas. Além desses movimentos exercidos apenas com o toque do leitor sobre a tela do dispositivo, há animações automáticas.

Percebe-se, desde o primeiro momento, que a proposta do e-book é diferenciada, optando por um apelo lúdico ao criar personagens próprios que se revestem dos personagens de outras histórias. Supõe-se que inventar novos personagens não elimina a necessidade de criar novas imagens mentais, pois é uma história contada por outra história. É como se cada Bean Kids assumisse um papel na história e se propusesse a contá-la, como se buscasse uma intimidade em laços de amizade. Além disso, é possível determinar um padrão gráfico para o design de todos os aplicativos, independentemente da história, ao mesmo tempo em que fortalece a marca e o posicionamento da empresa.

Inicialmente, o aplicativo possui uma tela de abertura e possibilita que o leitor opte por algumas configurações (Figura 2) assim que ele puxar uma cordinha que baixa a cortina. As linguagens disponíveis para o texto e narração em áudio são o inglês britânico e o espanhol. É possível escolher se a história será narrada através de áudio, ou se apenas o texto estará na tela. Também há a opção de autoplay, em que as telas do livro vão passando automaticamente, ou a possibilidade de tirar a seleção dessa opção, permitindo que somente o leitor determine o momento de mudar de tela. Essas opções, embora pareçam bastante básicas, dão ao leitor o poder de definir qual a ordem da leitura que deseja seguir e se sua interação será determinante ou não no fluxo da leitura.

Figura 2 - Abertura do aplicativo e opções de configuração.

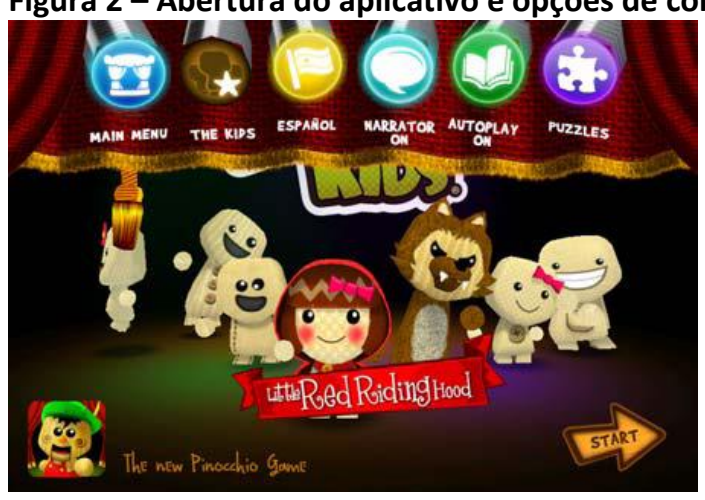

Fonte: BEAN BAG KIDS (2011).

Embora não permita uma completa autonomia, as interações propostas no aplicativo aproximam-se da leitura em superfície, na qual é possível compreender 
rapidamente a mensagem como um todo, controlar e manipular a sequência do conteúdo, se fixar em apenas uma parte da história e ainda ler todas as telas do início ao fim. O leitor precisa se sentir confortável e estimulado à prática da leitura, por isso a interface deve ser agradável e os links de navegação bastante funcionais. O que se verificou é que diante de tantas possibilidades de conexões, a navegação pelo conteúdo flui bem e os recursos de animações fazem parte do contexto da obra.

Analisando o design de comunicação visual do aplicativo, percebe-se que a concepção de um teatro de fantoches é traduzida nos elementos gráficos das ilustrações. Nas bordas de cada tela aparecem as pontas da cortina e entre cada tela a cortina desce, como em um encerramento de ato teatral. Inclusive, no final da história, os personagens/atores fazem uma reverência de agradecimento. Na abertura, há focos de luz, como se viessem de holofotes. Nenhuma ilustração busca representar a realidade através da fidelidade de traços, pelo contrário, não existe uma perfeita simetria e perspectiva dos objetos e, em cada cena, somente as peças indispensáveis para o entendimento daquele ponto da história aparecem. $O$ desenho dos personagens representa claramente bonecos de pano, fantoches, inclusive com a textura evidente de um tecido. Não há preocupação em desenhar os braços, as mãos ficam separadas do corpo e são as que mais se movimentam, como se pertencessem à outra pessoa, ao manipulador dos fantoches. A tipografia do texto é uma fonte fantasia, com inspiração manuscrita, com traços delicados, mas de boa leitura. Porém, o texto tem um tamanho pequeno e esta foi uma limitação encontrada no aplicativo, pois não há a possibilidade de trocar de fonte ou de tamanho, já que o texto é praticamente uma animação junto com as imagens.

De modo geral, o que se pode observar é que o projeto gráfico do e-book foi feito com bastante dedicação, sem procurar mimetizar um livro impresso, nem mesmo os livros impressos infantis, que já possuem apresentações diferentes. O que se objetivou foi aproveitar as possibilidades que os dispositivos digitais permitem, promovendo uma interação maior do leitor, não apenas restrita à leitura do texto.

Voltando à produção de novos sentidos no livro digital, enquanto a mídia processa a história, em princípio não se sabe o quê de mudanças ocorreu, por isso espera-se entender quais outros significados estão mediando o leitor e o livro. Para essa análise, a opção sem narrador foi escolhida, pois este, como outro agente do texto, traria outros significados a serem analisados, como a própria entonação da fala que já delimita muitos sentidos.

O aplicativo mostra-se então, com dois planos de imagem, um deles o do texto escrito, e o outro das ilustrações, imagens em 3D que servem somente para ilustrar. Não há autonomia entre os dois planos, ou seja, as ilustrações sozinhas não comunicam a mesma mensagem que o texto escrito. Analisando somente as cenas, sem ler os textos, poder-se-ia contar uma história um pouco diferente, como a seguinte descrição: a menina abanou para sua mãe e saiu por uma trilha a cheirar as flores; encontrou um lobo e o céu ficou escuro; o lobo foi embora, o céu clareou; o lobo, usando uma capa vermelha, vai até uma casa, uma velhinha atende, o lobo entra na casa; o lobo está deitado na cama com roupas iguais à da velhinha, a menina entra $e$ olha para o lobo; o lobo corre atrás da menina e o lenhador corre atrás do lobo; o lenhador pula em cima do lobo e a menina e a velhinha pulam ao fundo.

Considerando os significados ao analisar somente as imagens, parte-se para uma análise de cada cena. Na primeira delas (Figura 3), a personagem aparece 
saltitante na tela com dois quadros de informação além do texto inicial. Um dos quadros, apontando para ela, informa que ao tocar nos personagens é possível interagir com cada um e verificar novos movimentos. O outro quadro avisa que em cada tela da história há três estrelinhas para serem pegas e assim desbloquear a opção The Kids, do qual será falado mais adiante. Nenhuma imagem contextualiza a história ou o porquê da menina estar ali, no vazio. Ela possui apenas uma capa vermelha bem evidente. Com a visualização da imagem da capa vermelha, presente em todas as versões conhecidas e símbolo principal de representação da história, compreende-se que se trata da Chapeuzinho Vermelho. Ela também possui uma cestinha bem pequena na mão. Como nessa primeira cena não há mais nenhum elemento visual ao fundo, nota-se bem a cestinha, mas não se sabe para que ela serve.

Figura 3 - Cena 1.

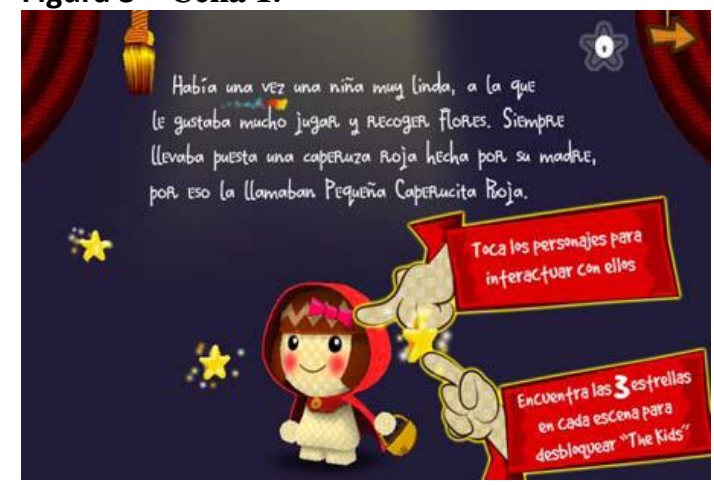

Fonte: BEAN BAG KIDS (2011).

$\mathrm{Na}$ cena seguinte (Figura 4), os personagens já aparecem dentro de determinado contexto, uma casinha na qual uma personagem abana para a Chapeuzinho Vermelho, que acena também. Não se sabe quem é essa personagem, mas por estar com um avental - representando a lida de casa -, e um coque no cabelo - representando ter mais idade -, imagina-se que possa ser a mãe da Chapeuzinho Vermelho. Também há um caminho de pedras pelo qual a menina caminha em direção às árvores. Dessa vez, com os outros elementos ao fundo, a cestinha passa despercebida.

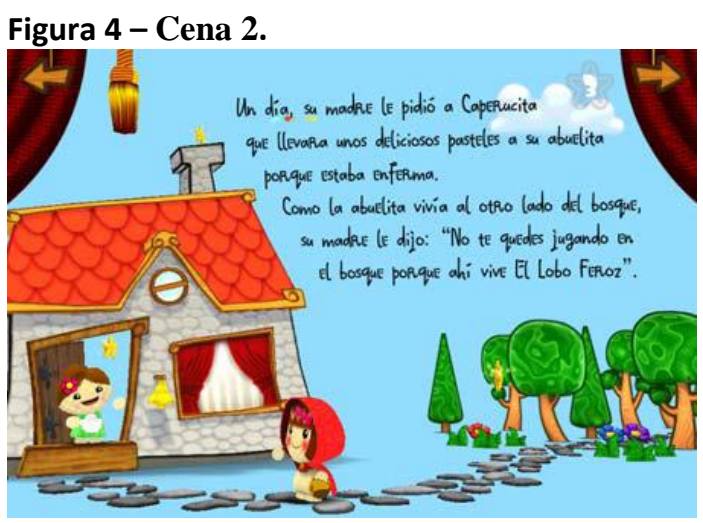

Fonte: BEAN BAG KIDS (2011).

A terceira cena (Figura 5) mantém uma sequência com a anterior, pois também mostra o caminho de pedras e as árvores. A Chapeuzinho Vermelho continua a 
caminhar, mas agora cheira cada flor. O lobo é visto pela primeira vez, e corre, escondendo-se entre as árvores.

Figura 5 - Cena 3.

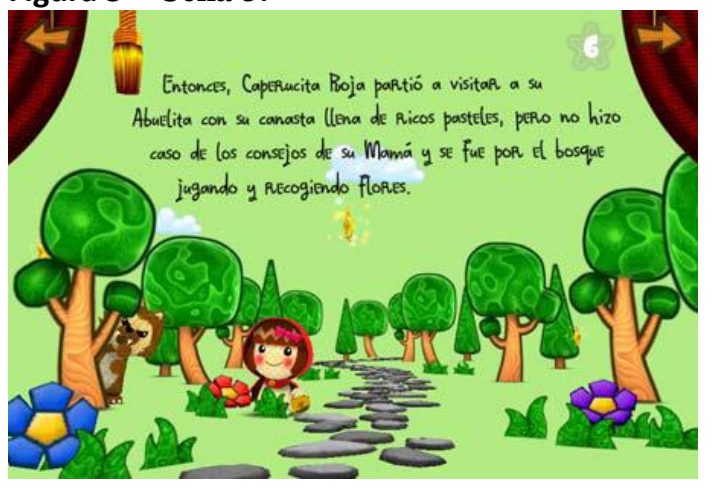

Fonte: BEAN BAG KIDS (2011).

Na cena quatro (Figura 6) quebra-se a sequência das imagens, pois o lobo, que já estava ali, entra novamente na cena, aproxima-se da Chapeuzinho Vermelho e o céu escurece. Aqui há uma dupla interpretação: quando o lobo se aproxima e o céu fica escuro, ou imagina-se que vai surgir uma tempestade e o lobo veio avisar a Chapeuzinho Vermelho disto, ou entende-se que o lobo é mau, pois sua presença faz o tempo piorar e as nuvens negras representam sua maldade. Essa representação é um ícone, entendido como um sinal de coisas ruins nas histórias. Muitos desenhos animados com bruxas e monstros utilizam o recurso de cores escuras e trovoadas para representar o ambiente onde moram os vilões.

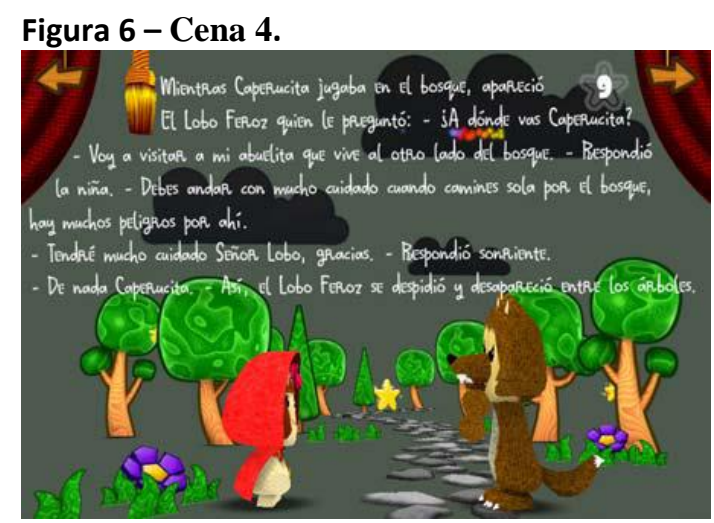

Fonte: BEAN BAG KIDS (2011).

Em sequência, na quinta cena (Figura 7) o lobo corre, vestindo uma capa vermelha igual à da Chapeuzinho Vermelho, até chegar a uma casa e bater na porta. Esta casa é bastante imponente, relativamente destoante de uma ambientação na floresta e de personagens mais humildes, dos quais trata a história original. A Chapeuzinho Vermelho aparece ao fundo, ainda próxima das flores. O que o lobo pretende vestido com uma capa igual? Na cena seguinte (Figura 8), outra personagem abre a porta e o lobo entra na casa. Antes disso ele faz uma careta e dá uma risada que parece malvada. Entende-se então, que o lobo tinha a intenção de se passar pela Chapeuzinho Vermelho. A personagem que abre a porta é a vovozinha da Chapeuzinho Vermelho, e assim se reconhece porque usa cabelos grisalhos, óculos e uma toquinha 
na cabeça. Bem ao fundo, tem um personagem que bate em uma árvore, possivelmente o lenhador.

Figura 7 - Cena 5.

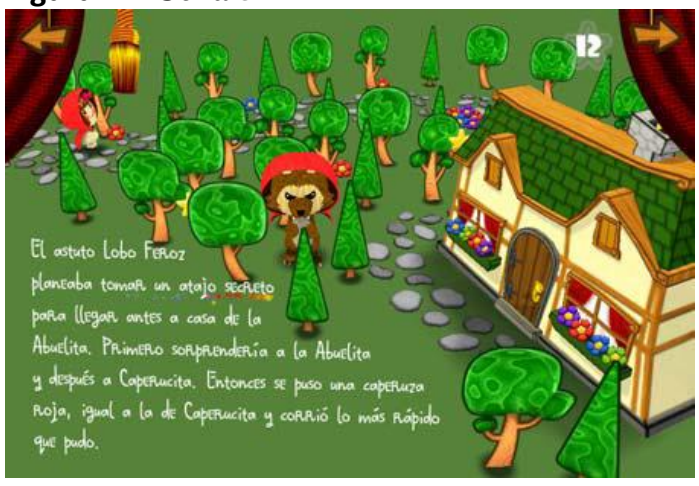

Fonte: BEAN BAG KIDS (2011).

Figura 8 - Cena 6.

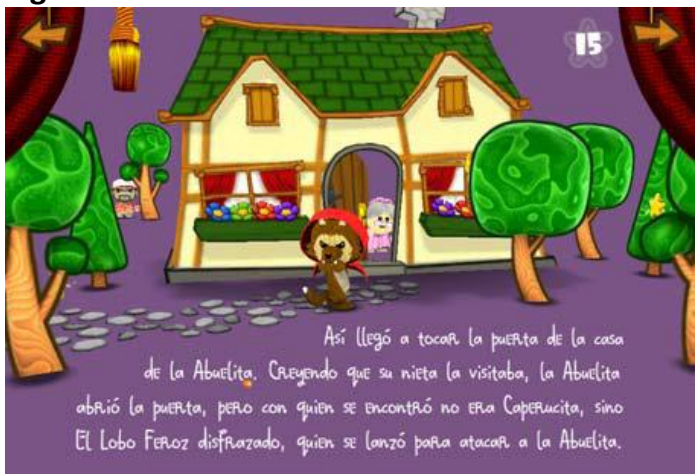

Fonte: BEAN BAG KIDS (2011).

Na próxima cena (Figura 9) o lobo está deitado na cama, no interior da casa, com óculos e touca parecidos com os da vovozinha que abre a porta na cena anterior. Aqui se percebe a importância do significado da vestimenta dos personagens como caracterização de quem eles são. Visualmente é possível entender que o lobo quis se passar, primeiramente pela Chapeuzinho Vermelho e depois pela vovozinha, apenas observando os elementos da sua roupa. Também nesta cena a Chapeuzinho Vermelho entra no quarto e olha para o lobo deitado na cama. Pela janela, continua-se visualizando o lenhador. A oitava cena é igual, mudando apenas o ângulo da imagem e o movimento dos personagens. A Chapeuzinho Vermelho aponta para o lobo, que toca em suas orelhas, olhos e boca, grunhindo no final, enquanto a Chapeuzinho Vermelho se abaixa. É neste momento que se fazem as exclamações tão conhecidas deste conto: "Que orelhas grandes você tem! Que olhos grandes você tem! Que boca grande você tem!". 
Figura 9 - Cena 7.

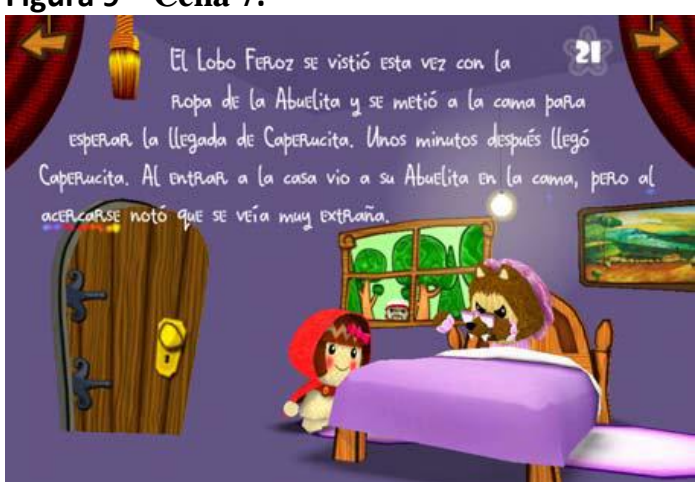

Fonte: BEAN BAG KIDS (2011).

Na cena nove (Figura 10) o lenhador corre atrás do lobo vestido de velhinha, que por sua vez corre atrás da Chapeuzinho Vermelho. Nota-se que é uma perseguição. Por fim, na última cena (Figura 11), vê-se que o lenhador ganhou a perseguição, pois pula em cima do lobo, que por sua vez está sem sua touca, jogada ao seu lado, representando sua derrota. A Chapeuzinho Vermelho e a vovozinha pulam ao fundo.

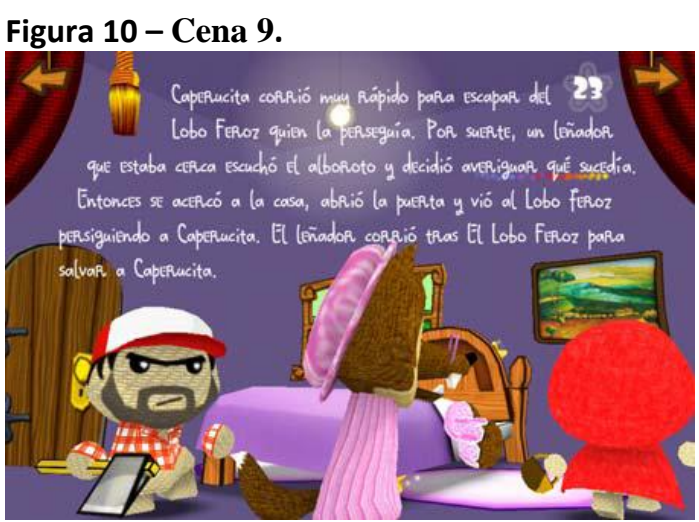

Fonte: BEAN BAG KIDS (2011).

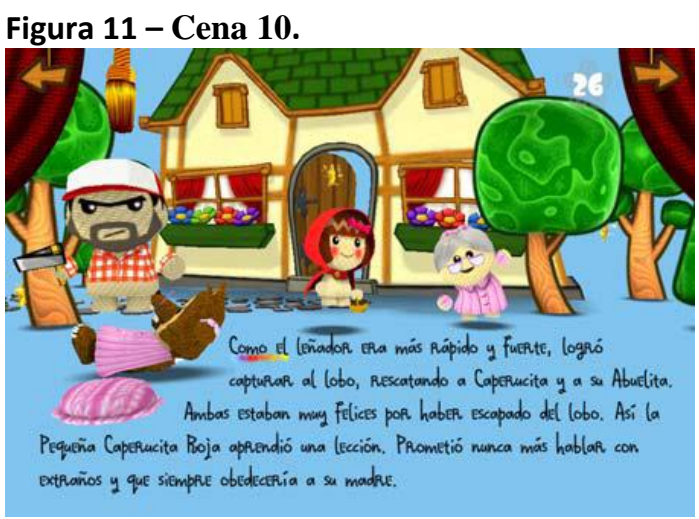

Fonte: BEAN BAG KIDS (2011).

Essa análise obtida somente com o foco nas ilustrações e animações recorta o entendimento. A palavra é mais ampla e ao ler os textos as questões ficam claras, como a utilidade da cestinha para carregar os pastéis, as intenções do lobo, quem são os personagens. As imagens não correspondem exatamente ao texto, pois não 
objetivam contar a história sozinhas. Ainda assim, essas animações trazem significados diferentes ao livro, que são possíveis devido à digitalidade do meio.

Embora se conheça a história, e sendo assim, o habitus contextualiza e facilita o entendimento das cenas, o livro digital traz aspectos diferentes, que mudam os sentidos. Quando a história vem por meio do aplicativo, e não pelo impresso, a sensação, o entendimento, é o de que se está lendo uma história diferente, que traz expectativas diferentes. O movimento e as ações dos personagens surpreendem, e cria-se com eles uma determinada afeição por meio da interatividade, uma amigabilidade com todos, até mesmo com o lobo, que não apresenta feição assustadora e feroz como o texto descreve, pelo contrário, resultando inclusive na dupla interpretação da cena quatro, em que surge a tempestade. A caracterização dos personagens, sempre saltitantes, cantarolantes e dando risadinhas, mostra um ambiente muito feliz, mascarando o terror de uma história que originalmente continha a morte como resultado final, ao menos a do lobo. Neste aplicativo, praticamente não há a presença do medo.

Os sentidos da história também mudam quando se destacam alguns elementos, como as roupas dos personagens - a capa vermelha e a touca da vovozinha - que fazem as intenções do lobo ficarem mais evidentes ao vesti-las. Também quando se minimiza outros, como a cestinha, que na história original é tão presente e marcante, significando o motivo principal pelo qual a Chapeuzinho Vermelho vai até a casa de sua vovozinha - levar produtos para que ela se recupere melhor de sua enfermidade -, enquanto neste livro digital, a cestinha leva apenas pastéis - que nem aparecem -, e é representada tão pequena ilustrativamente, que não significa o motivo principal da viagem da Chapeuzinho Vermelho. Muito mais marcante é o constante contato da personagem com as flores do caminho, grandes e coloridas.

Há ainda outro aspecto importante. As três estrelas que estão em todas as cenas, que ao serem coletadas por meio da interatividade do software, habilitam uma nova aba - The Kids - que mostra cada personagem individualmente. Essa aba não é necessária para entender a narrativa, pois se assim fosse, estaria habilitada desde o início, no entanto, o próprio aplicativo a ignora. Por outro lado, o leitor passa a procurar pelas estrelas e aprofunda a observação dos cenários e ilustrações. Inclusive é possível movimentar a tela do dispositivo fazendo com que o cenário se mova e mostre mais detalhes nas laterais. Mas quanto aos aspectos simbólicos, a presença das estrelas nas cenas é significativa, pois faz parte do próprio contexto das imagens. Elas estão por cima da casa, entre as árvores, embaixo da cama. Movimentam-se e brilham, reforçando a interpretação de um conto suave e amigável ao leitor. Também não fazem parte da história original: as estrelas fazem sentido somente neste aplicativo, nesta versão da história.

Portanto, concorda-se com a ideia de que o texto não existe fora do suporte e que os livros assumem diferentes significados dados pelo leitor, de acordo com esse suporte. Para o leitor do livro digital Little Red Riding Hood, a história apresenta novos sentidos, potencializados pelas interações hipermidiáticas, pela supressão e pelo acréscimo de elementos que não faziam parte da história original e que geram novos significados de compreensão que mediam o leitor e o livro digital. O que se percebeu com essa análise, é que no livro digital o leitor está dentro da história, a determina, e não fora dela, apenas sendo guiado pela linearidade do texto. 
Observando essa geração de novos sentidos, entende-se que é estratégico utilizar esse conhecimento para desenvolver projetos de design para livros digitais que utilizem uma abordagem que conquiste o leitor por meio de atributos que o livro impresso não possui. Deve ser dado ao leitor o poder de interagir e de determinar alguns acontecimentos, fazendo com que o leitor esteja dentro da própria história, pois é esta a principal vantagem que o dispositivo eletrônico possibilita, capaz de modificar o significado de todas as histórias.

\section{CONCLUSÃO}

Este artigo abordou questionamentos no âmbito dos processos midiáticos e da leitura digital através de uma abordagem que considerou o e-book como um novo produto no campo da mídia e do design. Seu suporte eletrônico se torna um meio capaz de transformar a formatação convencional do livro e promover novas práticas de leitura com o uso de recursos digitais hipermidiáticos interativos que geram um ato de leitura contrário à linearidade. Além disso, consideraram-se as possibilidades diferenciadas que a digitalidade do suporte proporciona, como capazes de gerar novos sentidos na leitura. Esses novos significados do conteúdo foram exemplificados através da análise do e-book Little Red Riding Hood, cuja história apresentou novos sentidos que mediam o leitor e o livro digital, através da supressão e acréscimo de elementos que não faziam parte da história original, além do uso dos recursos digitais interativos.

Considerou-se também, que os efeitos de sentido gerados pela leitura digital podem determinar quais estratégias de design devem ser utilizadas na criação de sistemas produto-serviço para o mercado do livro digital. Ou seja, as análises realizadas não são feitas para encerrarem-se em si mesmas, mas sim para serem utilizadas no design estratégico como insumos de projeto de sistemas produto-serviço. A visão dessas análises permite que a estratégia esteja presente desde o início da formulação do problema e das pesquisas contextuais, até o final do projeto, com a apresentação de soluções.

Considerando que o habitus facilita o entendimento da mensagem de um livro digital, mas objetivando-se a mudança de sentidos, alguns pontos poderiam fortemente ser considerados no projeto, como a supressão e o destaque de determinados elementos da história original que podem se manifestar de modo diferenciado na mídia digital, o acréscimo de elementos novos que proporcionem maior interatividade e a disponibilidade de acesso para o leitor controlar determinados pontos do texto.

Entende-se que uma continuação da pesquisa deste artigo possibilitaria a submissão do aplicativo à análise de outros leitores, adultos e também crianças, de modo a amplificar os conceitos interpretados e a compreensão de outros sentidos gerados. Outro aspecto que também poderiam ser abordados em futuras análises é o estímulo de recolhimento das estrelinhas como uma caça ao tesouro, já que ao final das coletas o leitor recebe uma recompensa ao poder interagir com cada um dos personagens na aba The Kids. Nesse mesmo contexto de jogos inseridos no livro, o aplicativo analisado também possui 16 quebra-cabeças com imagens que fazem parte da história, estendendo-a para além do texto principal. A gameficação dos livros digitais também é assunto para outro artigo.

Somando-se às discussões correntes sobre o livro digital, este trabalho conseguiu traçar caminhos de análise capazes de sair do lugar comum sobre a vida ou 
morte do livro impresso, demonstrando que é preciso vislumbrar o leitor de amanhã e projetar hoje, tendo a consciência de que o livro digital é um produto novo e um tanto desconhecido, capaz de viabilizar o que nem mesmo se imagina. Por isso, precisa-se de pesquisas na área, que sirvam como base para futuros projetos verdadeiramente inovadores no campo midiático e do design, capazes de transformar com grande impacto as práticas de leitura.

\section{REFERÊNCIAS}

BEAN BAG KIDS, 2011. Disponível em: <http://www.thebeanbagkids.com/index.php>. Acesso em: 28 out. 2012.

BOURDIEU, P. O poder simbólico. Rio de Janeiro: Bertrand Brasil, 1998.

CHARTIER, Roger. Práticas da leitura. São Paulo: estação Liberdade, 1996.

FARBIARZ, Alexandre. FARBIARZ, Jackeline Lima. Do códice ao e-book: o texto e o suporte, p.113-138. In: Design Olhares sobre o Livro. Rio de Janeiro, RJ: Editora Novas Ideias, 2010. 192 p.

FRASCARA, J. Communication Design: Principles, Tethods, and Practice. New York: Allworth Press, 2004.

FLUSSER, V. O mundo codificado: por uma filosofia do design e da comunicação. São Paulo: Cosac Naify, 2007.

FURTADO, José Afonso. Livro e leitura no novo ambiente digital. In: Instituto de Educação Universidade de Lisboa, 2002. Disponível em: <http://www.educ.fc.ul.pt/ hyper/resources/afurtado/index.htm>. Publicado em: 15 nov. 2002. Acesso em: 02 out. 2011.

GOULEMOT, Jean Marie. Da leitura como produção de sentidos. In: CHARTIER, Roger. Práticas de leitura. São Paulo: estação Liberdade, 1996, pp. 107-116.

JENSEN, K.B. La Semiótica social de la comunicación de masas. Barcelona: Bosch, 1997.

LABARRE, Albert. História do Livro. São Paulo, SP: Cultrix, 1981.

MCLUHAN, M. Os meios de comunicação como extensões do homem. São Paulo: Cultrix, 2007.

RODRIGUES, A. A experiência, modernidade e campo dos media. 1999. Disponível em: <http://www.bocc.uff.br/pag/Rodrigues-adriano-expcampmedia.pdf>.

SANTAELLA, Lúcia. Potenciais e desafios para a comunicação e inovação. Comunicação e Inovação. São Caetano do sul, v. 8, n. 14, jan./jun. 2007. 